\title{
Glucocorticoid-cholinergic interactions in the dorsal striatum in memory consolidation of inhibitory avoidance training
}

\author{
Oscar Sánchez-Resendis ${ }^{1}$, Andrea C. Medina ${ }^{1}$, Norma Serafín ${ }^{1}$, Roberto A. Prado-Alcalá1, \\ Benno Roozendaal ${ }^{2}$ and Gina L. Quirarte ${ }^{1 *}$
}

\begin{abstract}
1 Departamento de Neurobiología Conductual y Cognitiva, Instituto de Neurobiología, Universidad Nacional Autónoma de México, Querétaro, México
${ }^{2}$ Departamento de Neurobiología Conductual y Cognitiva, Instituto de Neurobiología, Universidad Nacional Autónoma de México, Campus Juriquilla

Querétaro, México
\end{abstract}

Edited by:

Antonella Gasbarri, University of

L'Aquila, Italy

Reviewed by:

Oliver T. Wolf, Ruhr University

Bochum, Germany

Rafael Roesler, Federal University of

Rio Grande do Sul, Brazil

*Correspondence:

Gina L. Quirarte, Instituto de Neurobiología, Universidad Nacional

Autónoma de México, Campus

Juriquilla, Boulevard Juriquilla 3001,

Querétaro, Qro. 76230, México.

e-mail: ginaqui@unam.mx
Extensive evidence indicates that glucocorticoid hormones act in a variety of brain regions to enhance the consolidation of memory of emotionally motivated training experiences. We previously reported that corticosterone, the major glucocorticoid in the rat, administered into the dorsal striatum immediately after inhibitory avoidance training dose-dependently enhances memory consolidation of this training. There is also abundant evidence that the intrinsic cholinergic system of the dorsal striatum is importantly involved in memory consolidation of inhibitory avoidance training. However, it is presently unknown whether these two neuromodulatory systems interact within the dorsal striatum in the formation of long-term memory. To address this issue, we first investigated in male Wistar rats whether the muscarinic receptor agonist oxotremorine administered into the dorsal striatum immediately after inhibitory avoidance training enhances $48 \mathrm{~h}$ retention of the training. Subsequently, we examined whether an attenuation of glucocorticoid signaling by either a systemic administration of the corticosterone-synthesis inhibitor metyrapone or an intra-striatal infusion of the glucocorticoid receptor (GR) antagonist $\mathrm{RU} 38486$ would block the memory enhancement induced by oxotremorine. Our findings indicate that oxotremorine dose-dependently enhanced $48 \mathrm{~h}$ retention latencies, but that the administration of either metyrapone or RU 38486 prevented the memory-enhancing effect of oxotremorine. In the last experiment, corticosterone was infused into the dorsal striatum together with the muscarinic receptor antagonist scopolamine immediately after inhibitory avoidance training. Scopolamine blocked the enhancing effect of corticosterone on $48 \mathrm{~h}$ retention performance. These findings indicate that there are mutual interactions between glucocorticoids and the striatal cholinergic system in enhancing the consolidation of memory of inhibitory avoidance training.

Keywords: glucocorticoid receptor, caudate nucleus, corticosterone, oxotremorine, scopolamine, stress hormone

\section{INTRODUCTION}

It is well established that glucocorticoid hormones (corticosterone in rodents, cortisol in humans), released from the adrenal cortex during stressful episodes, act in a neurocircuitry of interconnected brain regions to enhance the consolidation of memory of emotionally arousing training experiences (de Kloet et al., 1999; Roozendaal, 2002; McGaugh, 2004; Miranda et al., 2008; Roozendaal et al., 2009; Joëls et al., 2011; Schwabe et al., 2012). For example, corticosterone or a specific glucocorticoid receptor (GR) agonist administered into either the basolateral complex of the amygdala (BLA) or hippocampus is known to enhance memory consolidation of inhibitory avoidance training or of other training with a strong contextual component (Roozendaal and McGaugh, 1997a,b). Recently, we reported that the dorsal striatum is another target structure for glucocorticoids in modulating memory consolidation of inhibitory avoidance training (Medina et al., 2007). However, as glucocorticoid infusions into the dorsal striatum failed to enhance memory of either the footshock or contextual aspects of inhibitory avoidance training (Medina et al., 2007), these findings suggest that corticosterone might act within the dorsal striatum to specifically enhance the consolidation of memory of procedural aspects of inhibitory avoidance training, consistent with the evidence that the dorsal striatum is crucially involved in memory formation of procedural or non-declarative training (Packard and White, 1991; McDonald and White, 1993; Packard et al., 1994; Packard and Knowlton, 2002; Prado-Alcalá et al., 2003; White, 2009).

One of the neurotransmitter systems of the dorsal striatum that has received most attention is its intrinsic cholinergic system. On the one hand, it has been shown that striatal cholinergic interneurons are involved in motor control, as seen in humans where dysfunction of this complex system leads to movement disorders such as Huntington's and Parkinson's disease (Sandberg et al., 1984; Galarraga et al., 1999; Pisani et al., 2001; Wilson, 2004; Graybiel, 2008). On the other hand, muscarinic receptor antagonists administered into the dorsal striatum are known to induce 
retrograde amnesia of inhibitory avoidance training (Haycock et al., 1973; Prado-Alcalá et al., 1980) in a time- and dosedependent fashion (Prado-Alcalá et al., 1984b, 1985; Giordano and Prado-Alcalá, 1986), whereas the intra-striatal administration of muscarinic receptor agonists improves retention of this training (Solana-Figueroa and Prado-Alcalá, 1990). Additional support for the view that the striatal cholinergic system modulates memory consolidation came from experiments indicating that local activation or blockade of the cholinergic system either enhances or impairs memory of active avoidance, lever pressing, and autoshaping (Neill and Grossman, 1970; Prado-Alcalá et al., 1984a; Bermúdez-Rattoni et al., 1986).

Several findings indicate that stress exposure influences activity of the cholinergic system in the brain (Mark et al., 1996; Ortega et al., 1996; Gold, 2003) as well as that the stress associated with certain training procedures can alter cholinergic activity (Tajima et al., 1996; Orsini et al., 2001; Helm et al., 2004). However, much less is known of whether such stress effects on cholinergic activity are mediated by glucocorticoid actions. Given that both glucocorticoids and the cholinergic system play an important role within the dorsal striatum in memory consolidation, the present study investigated whether glucocorticoids and the striatal cholinergic system interact in modulating memory consolidation of inhibitory avoidance training. To address this issue, we first investigated whether the muscarinic receptor agonist oxotremorine administered into the dorsal striatum immediately after inhibitory avoidance training enhances the consolidation of memory of the training experience. Subsequently, we examined whether either systemic administration of the corticosteronesynthesis inhibitor metyrapone, suppressing the endogenous corticosterone response, or an infusion of the GR antagonist RU 38486 directly into the dorsal striatum would block the enhancing effect of oxotremorine on inhibitory avoidance memory. In the last experiment, we used a complementary approach and investigated whether a blockade of muscarinic receptors in the dorsal striatum after inhibitory avoidance training would prevent the memory enhancement induced by corticosterone.

\section{MATERIALS AND METHODS ANIMALS}

Adult male Wistar rats (250-350g at the time of surgery), obtained from the breeding colony of the Instituto de Neurobiología, Universidad Nacional Autónoma de México, were housed individually in acrylic cages with food and tap water available ad libitum. They were maintained on a 12/12 h light-dark cycle (lights on at 7:00 h) and a constant room temperature of $21^{\circ} \mathrm{C}$. The rats were randomly assigned to the different experimental groups, with initial sample sizes ranging from 10 to 12 rats per group. All experimental procedures were approved by the Animal Ethics Committee of the Instituto de Neurobiología, Universidad Nacional Autónoma de México, and were in compliance with the "Principles of Laboratory Animal Care" of the National Institutes of Health.

\section{SURGERY}

Animals, adapted to the colony room for at least one week, were anesthetized with sodium pentobarbital $(50 \mathrm{mg} / \mathrm{kg}$ of body weight, ip) and given atropine sulfate $(0.4 \mathrm{mg} / \mathrm{kg}$, ip) to maintain respiration. The skull was positioned in a stereotaxic frame (Stoelting, Co. IL) and two stainless-steel guide cannulae $(11 \mathrm{~mm}$ long, 23 gauge) were implanted into the anterior division of the dorsal striatum (coordinates: anteroposterior, $0.0 \mathrm{~mm}$ from Bregma; mediolateral, $\pm 3.2 \mathrm{~mm}$ from midline; dorsoventral, $4.2 \mathrm{~mm}$ below skull surface, incisor bar $-3.3 \mathrm{~mm}$ from interaural line) according to the atlas of Paxinos and Watson (2005). The cannulae were affixed to the skull with two anchoring screws and dental cement. Stylets ( $11 \mathrm{~mm}$ long 00 -insect dissection pins) were inserted into each cannula to maintain patency and were removed only for the infusion of drugs. After surgery, the rats received a subcutaneous $1 \mathrm{ml}$ injection of saline to prevent dehydration and were retained within an incubator until recovered from anesthesia and were then returned to their home cages. The rats were allowed to recover for a minimum of seven days before initiation of training and were handled three times for 3 min each during this period to accustom them to the infusion procedures.

\section{INHIBITORY AVOIDANCE APPARATUS AND PROCEDURES}

The rats were trained and tested in an inhibitory avoidance apparatus consisting of a trough-shaped alley $(20 \mathrm{~cm}$ wide at the top and $8 \mathrm{~cm}$ wide at the bottom) with two distinct compartments of the same size $(30 \times 30 \times 30 \mathrm{~cm})$, separated by a sliding door. The starting compartment had walls and lid made of red-colored acrylic with a floor of stainless steel bars $(6 \mathrm{~mm}$ in diameter, separated by $9 \mathrm{~mm}$ ) and was illuminated by a $10-\mathrm{W}$ light bulb. The shock compartment was made of two electrifiable stainless steel plates and was not illuminated with its end walls and lid constructed of red-colored acrylic. In the middle of the floor, a $1.5 \mathrm{~cm}$ slot separated the two stainless steel plates that made up the walls and floor. The apparatus was located inside a dark, soundattenuated room provided with background masking noise (San Diego Instruments).

For training, the rat was placed into the starting compartment of the apparatus and $10 \mathrm{~s}$ later the sliding door was opened and the latency to enter the dark compartment was recorded. After the animal stepped into the shock compartment with all four paws, the door was closed and a single, inescapable footshock $(0.60 \mathrm{~mA}$, $1 \mathrm{~s})$ was delivered using a precision-regulated animal shock generator (Coulbourn Instruments, USA). Automated equipment controlled the duration of the footshock and measured the rat's latency to cross from one compartment to the other. The rat was removed from the shock compartment $10 \mathrm{~s}$ after termination of the footshock and, after drug treatment, returned to the home cage. On the $48 \mathrm{~h}$ retention test, as on the training session, the latency to re-enter the shock compartment with all four paws (maximum latency of $600 \mathrm{~s}$ ) was recorded and used as a measure of retention. Longer latencies were interpreted as indicating better retention. Shock was not administered on the retention test trial.

\section{DRUG AND INFUSION PROCEDURES}

The muscarinic receptor agonist oxotremorine $(0.15,0.30,0.45$, 0.60 , or $1.0 \mu \mathrm{g}$ in $1 \mu \mathrm{l}$, Sigma-Aldrich) was dissolved in sodium phosphate buffer, $\mathrm{pH} 7.4$, and infused into the dorsal striatum immediately after inhibitory avoidance training. Bilateral infusions of drug, or an equivalent volume of vehicle, were made using 
30 -gauge injection needles connected to $10 \mu \mathrm{l}$ Hamilton microsyringes by polyethylene (PE-20) tubing, driven by an automated microinfusion pump (model 220i, WPI). The injection needles protruded $2 \mathrm{~mm}$ beyond the tip of the cannula and an injection volume of $1 \mu \mathrm{l}$ per hemisphere was delivered over $1 \mathrm{~min}$. The injection needles were retained within the cannulae for an additional minute following drug infusion to maximize diffusion and prevent backflow of drug into the cannulae.

For adrenocortical suppression, the 11- $\beta$-hydroxylase inhibitor metyrapone (2-methyl-1,2-di-3-pyridyl-1-propanone; $50 \mathrm{mg} / \mathrm{kg}$; Sigma-Aldrich) was injected subcutaneously in a volume of $2 \mathrm{ml} / \mathrm{kg} 90 \mathrm{~min}$ before training. Metyrapone was first dissolved in $100 \%$ polyethylene glycol and subsequently diluted with $0.9 \%$ saline to reach the appropriate concentration. The final concentration of polyethylene glycol was $40 \%$. The vehicle control contained the same polyethylene glycol concentration. The dose of metyrapone was selected on the basis of previous findings indicating that it effectively blocks stress-induced increases in circulating levels of corticosterone without affecting basal levels (Roozendaal et al., 1996). In this study we did not measure corticosterone levels because there is evidence showing that the dose of metyrapone that we used $(50 \mathrm{mg} / \mathrm{kg})$ induced a significant reduction of peripheral corticosterone levels and produces memory impairment in different tasks such as passive avoidance in chicks (Loscertales et al., 1997), conditioned taste aversion (Miranda et al., 2008), spatial memory (Akirav et al., 2004), and blocks the memory enhancing effects of amphetamine or ephinephrine (Roozendaal et al., 1996) as well as the memory facilitation by stressful conditions during learning (Conboy and Sandi, 2010).

The GR antagonist RU 38486 (17 $\beta$-hydroxy-11 $\beta$-(4dimethylaminophenyl)-17 $\alpha$-(1-propynyl)-estra-4,9-dien-3-one; $10 \mathrm{ng}$ in $1 \mu \mathrm{l}$; Sigma-Aldrich) was microinjected into the dorsal striatum $15 \mathrm{~min}$ before training. RU 38486 was first dissolved in $100 \%$ ethanol and subsequently diluted in saline. The final ethanol concentration was 2\%. The dose of RU 38486 was selected on the basis of previous findings indicating that, when administered into the dorsal striatum, it blocks memory enhancement of inhibitory avoidance training induced by concurrently administered corticosterone (Medina et al., 2007).
For the last experiment, corticosterone (10 or $30 \mathrm{ng}$ in $1 \mu \mathrm{l}$; Sigma-Aldrich) was administered into the dorsal striatum together with the muscarinic receptor antagonist scopolamine (30 $\mathrm{g}$; Sigma-Aldrich) immediately after inhibitory avoidance training. Corticosterone and scopolamine were dissolved in a vehicle containing $2 \%$ ethanol in phosphate buffer, $\mathrm{pH} 7.4$. The dose of corticosterone was selected on the basis of prior experiments (Medina et al., 2007).

\section{HISTOLOGY}

After completion of behavioral testing, the rats were deeply anesthetized with sodium pentobarbital and perfused transcardially with isotonic saline followed by $4 \%$ formaldehyde. After decapitation, the brains were removed and immersed in a $4 \%$ formaldehyde solution for at least five days. Sections of $50 \mu \mathrm{m}$ were cut on a cryostat and stained with cresyl-violet. The sections were examined under a light microscope, and the location of injection needle tips within the dorsal striatum was determined. Histological analysis revealed that the injection needle tips of seven rats were not located within the boundaries of the targeted area. The data of these animals were not included in the statistical analyses. Figure 1 shows the location of the injection needle tips within the dorsal striatum of rats included in the statistical analyses.

\section{STATISTICS}

Data are presented as median + interquartile ranges. Inhibitory avoidance training and retention latencies were analyzed with independent Kruskal-Wallis analyses of variance. When appropriate, Mann-Whitney U-tests were used to make comparisons between any two groups. A probability level of $<0.05$ was accepted as statistical significance. The number of rats per group is indicated in the figure legends.

\section{RESULTS \\ IMMEDIATE POST-TRAINING INFUSIONS OF OXOTREMORINE INTO THE DORSAL STRIATUM DOSE-DEPENDENTLY ENHANCE INHIBITORY AVOIDANCE MEMORY}

The first experiment investigated whether bilateral infusions of the muscarinic receptor agonist oxotremorine $(0.15,0.3,0.45,0.6$

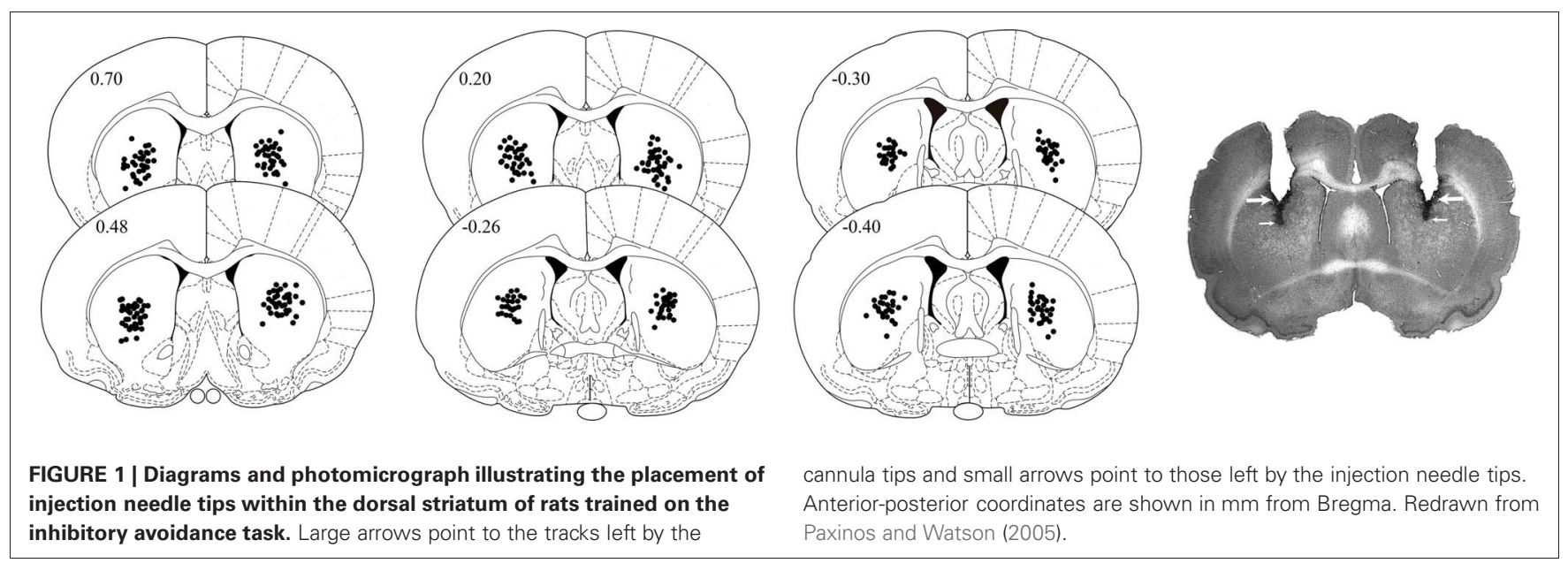


or $1.0 \mu \mathrm{g}$ in $1 \mu \mathrm{l}$ ) given immediately after inhibitory avoidance training enhance performance on a $48 \mathrm{~h}$ retention test. Entrance latencies during the training trial, before footshock or drug treatment, did not differ among groups $\left[H_{(5)}=5.15, P=0.39\right.$; data not shown]. As is shown in Figure 2, Kruskal-Wallis test for $48 \mathrm{~h}$ retention latencies revealed a significant group effect $\left[H_{(5)}=\right.$ 18.24, $P<0.005]$. Oxotremorine in a dose of $0.3 \mu \mathrm{g}$ produced

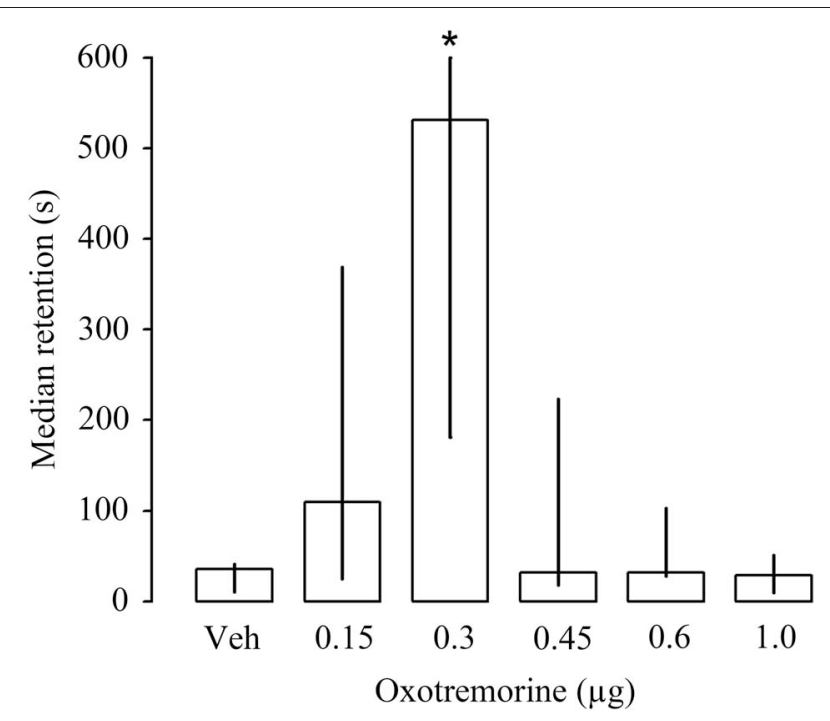

FIGURE 2 | Median latencies and interquartile ranges, in seconds on the $48 \mathrm{~h}$ inhibitory avoidance retention test of rats given immediate post-training infusions of either vehicle (Veh) or the muscarinic receptor agonist oxotremorine $(0.15,0.3,0.45,0.6$, and $1.0 \mu \mathrm{g})$ into the dorsal striatum. The group that received the $0.3 \mu \mathrm{g}$ dose of oxotremorine showed longer retention latencies. ${ }^{*} P<0.05$ as compared to all other groups ( $N=10$ rats/group). significantly longer retention latencies than those of rats treated with vehicle $(P<0.05)$. Lower or higher doses of oxotremorine did not alter retention performance.

\section{OXOTREMORINE-INDUCED MEMORY ENHANCEMENT DEPENDS ON CONCURRENT GLUCOCORTICOID ACTIVATION}

In this experiment we investigated whether an attenuation of glucocorticoid signaling alters the memory-enhancing effects of post-training muscarinic cholinergic activation within the dorsal striatum. In the first part, rats were injected subcutaneously with the corticosterone-synthesis inhibitor metyrapone $(50 \mathrm{mg} / \mathrm{kg})$ or vehicle $90 \mathrm{~min}$ before inhibitory avoidance training, followed by a bilateral intra-striatal infusion of oxotremorine $(0.3$ or $1.0 \mu \mathrm{g})$ immediately after the training trial. Entrance latencies during training did not differ among groups $\left[H_{(5)}=6.45 P=0.26\right]$. However, there were significant group differences in $48 \mathrm{~h}$ retention latencies $\left[H_{(5)}=20.48, P=0.001\right]$. Consistent with the findings of the first experiment, Mann-Whitney U-tests indicated that rats treated with the $0.3 \mu \mathrm{g}$ dose of oxotremorine had longer retention latencies than rats administered vehicle or the higher dose of oxotremorine ( $P$ 's ranging from 0.05 to $0.005)$. Metyrapone treatment blocked the retention enhancement induced by intra-striatal oxotremorine administration and retention latencies of the metyrapone-oxotremorine $(0.3 \mu \mathrm{g})$ group were significantly shorter than those of the vehicleoxotremorine $(0.3 \mu \mathrm{g})$ group $(P<0.002)$ (Figure 3A).

In the second part of the experiment, the GR antagonist RU 38486 (10 ng) was administered bilaterally into the dorsal striatum $15 \mathrm{~min}$ before training, followed by oxotremorine $(0.3$ or $1.0 \mu \mathrm{g})$ immediately after the training. Entrance latencies during the training trial did not differ among groups $\left[H_{(5)}=7.61\right.$ $P=0.17]$. During $48 \mathrm{~h}$ retention testing, significant group differences were found $\left[H_{(5)}=17.49, P<0.005\right]$. Rats treated with

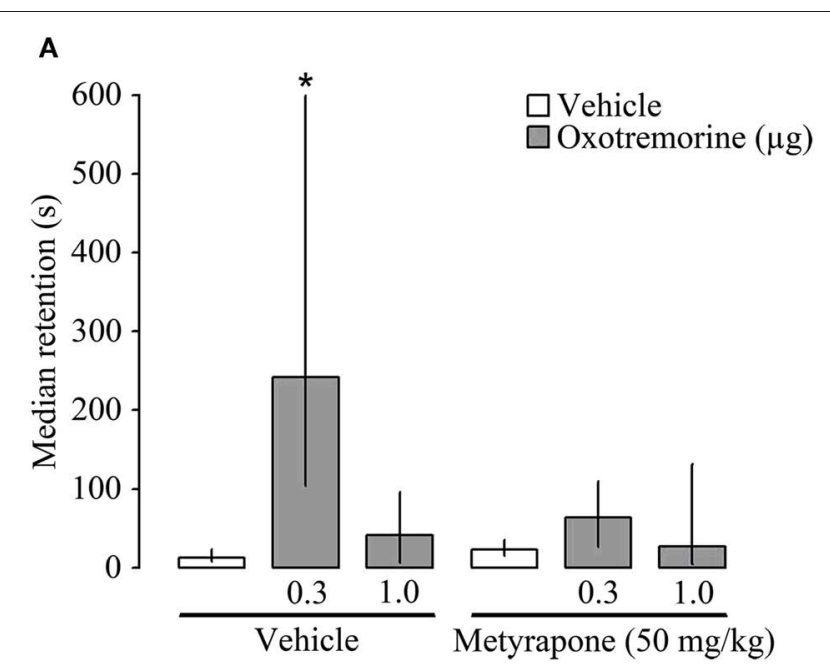

FIGURE 3 | Median latencies and interquartile ranges, in seconds on the $48 \mathrm{~h}$ inhibitory avoidance retention test. (A) Post-training infusion of the muscarinic receptor agonist oxotremorine $(0.3 \mu \mathrm{g})$ into the dorsal striatum enhanced $48 \mathrm{~h}$ retention performance and a pre-training systemic administration of the $11 \beta$-hydroxylase inhibitor metyrapone $(50 \mathrm{mg} / \mathrm{kg}$ )

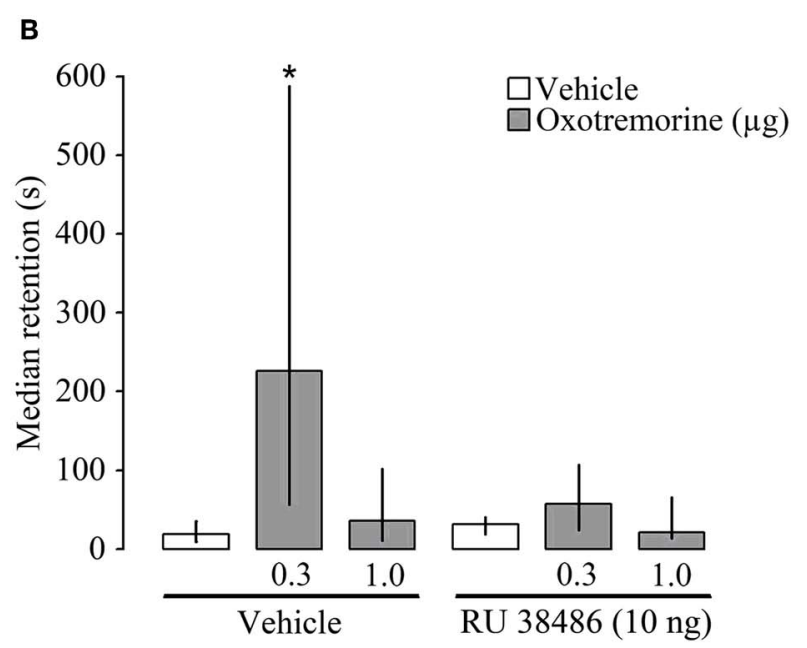

blocked this retention enhancement. (B) The glucocorticoid receptor (GR) antagonist RU 38486 (10 ng) administered into the dorsal striatum $15 \mathrm{~min}$ before inhibitory avoidance training also blocked the memory-enhancing effect of oxotremorine $(0.3 \mu \mathrm{g})$ given immediately posttraining into the dorsal striatum. ${ }^{*} P<0.05$ as compared to the vehicle group ( $N=10$ rats/group). 
the lower dose of oxotremorine $(0.3 \mu \mathrm{g})$ had significantly longer retention latencies than rats treated with either vehicle or the higher dose of oxotremorine ( $P$ 's $<0.002$ and 0.05 , respectively). In rats also administered RU 38486, the memory-enhancing effect of oxotremorine was abolished and retention latencies of the RU 38486-oxotremorine $(0.3 \mu \mathrm{g})$ group were significantly shorter than those of the vehicle-oxotremorine $(0.3 \mu \mathrm{g})$ group $(P<0.05)$ (Figure 3B).

\section{CORTICOSTERONE-INDUCED MEMORY ENHANCEMENT DEPENDS ON CHOLINERGIC ACTIVITY WITHIN THE DORSAL STRIATUM}

To explore further the nature of the interaction between glucocorticoids and the cholinergic system in memory consolidation, corticosterone (10 or $30 \mathrm{ng}$ ) was administered bilaterally into the dorsal striatum either alone or together with the muscarinic receptor antagonist scopolamine $(30 \mu \mathrm{g})$ immediately after inhibitory avoidance training. Entrance latencies during the training trial, before footshock or drug treatment, did not differ among groups $\left[H_{(5)}=5.15 P=0.40\right]$. As is shown in Figure 4, Kruskal-Wallis analysis revealed significant differences in $48 \mathrm{~h}$ retention latencies $\left[H_{(5)}=11.28, P<0.05\right]$. The $10 \mathrm{ng}$ dose of corticosterone, but not the $30 \mathrm{ng}$ dose, enhanced retention latencies $(P<0.05)$. However, scopolamine treatment blocked the memory-enhancing effect of corticosterone. Retention latencies of rats given corticosterone (10 ng) together with scopolamine were significantly shorter than those of rats given that dose of corticosterone alone $(P<0.05)$.

\section{DISCUSSION}

The present findings indicate that glucocorticoids and the cholinergic system of the dorsal striatum interact in enhancing the consolidation of memory of inhibitory avoidance training. Microinfusion of the muscarinic receptor agonist oxotremorine into the dorsal striatum immediately after inhibitory avoidance

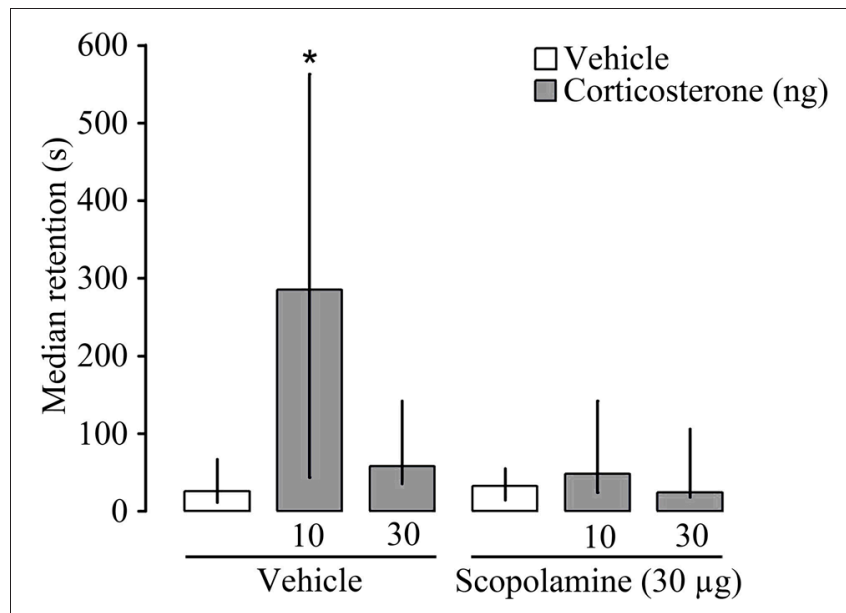

FIGURE 4 | Median latencies and interquartile ranges, in seconds on the $48 \mathrm{~h}$ inhibitory avoidance retention test. The muscarinic receptor antagonist scopolamine $(30 \mu \mathrm{g})$ administered into the dorsal striatum immediately after inhibitory avoidance training blocked the memory-enhancing effect of concurrently administered corticosterone $* P<0.05$ as compared to the vehicle group ( $N=8-11$ rats/group). training dose-dependently enhanced $48 \mathrm{~h}$ retention performance. However, and importantly, an attenuation of glucocorticoid signaling with either a systemic administration of the corticosteronesynthesis inhibitor metyrapone or an intra-striatal administration of the GR antagonist RU 38486 blocked the memory-enhancing effect of oxotremorine. Further, we found that corticosterone enhanced memory when infused into the dorsal striatum after inhibitory avoidance training and that this corticosterone effect was blocked in rats concurrently administered the muscarinic receptor antagonist scopolamine.

The current finding that oxotremorine administered into the dorsal striatum after inhibitory avoidance training enhanced $48 \mathrm{~h}$ retention performance is consistent with extensive evidence from other studies indicating that post-training activation of muscarinic receptors in this brain region enhances retention of inhibitory avoidance training (Solana-Figueroa and Prado-Alcalá, 1990; Ortega et al., 1996; Packard et al., 1996) or of training on several other learning tasks (Brimblecombe, 1964; Baratti et al., 1979), whereas a post-training blockade of muscarinic receptors impairs retention of inhibitory avoidance and other training (Prado-Alcalá et al., 1984b; Giordano and Prado-Alcalá, 1986). Similarly, our finding that post-training infusions of corticosterone into the dorsal striatum enhance retention of inhibitory avoidance training is consistent with other recent findings from our laboratory (Medina et al., 2007). As these memory-enhancing drugs were administered after the training trial, non-specific drug influences on the acquisition (i.e., footshock sensitivity, locomotion, attention, arousal, etc.) are excluded. Also, because these drugs are effective at enhancing long-term retention only when given within several hours after the training experience (Flood et al., 1978; Giordano and Prado-Alcalá, 1986; Sandi and Rose, 1994), the present findings strongly suggest that these drug effects on retention performance are due selectively to influences on the consolidation of long-term memory.

The aim of the present experiments was to investigate whether the glucocorticoid and cholinergic systems of the dorsal striatum interact in modulating memory consolidation of inhibitory avoidance training. The interest of this question stems from previous work indicating that stressful stimulation, either exogenously or induced by the training procedure, can alter cholinergic activity in the brain. Stressful stimuli are known to promote the release of acetylcholine in the hippocampus (Mark et al., 1996), which might directly contribute to the enhancing effects of stress on synaptic plasticity and memory (Shinoe et al., 2005). In addition to such immediate effects of stress-induced acetylcholine release on synaptic plasticity, stressful experiences might also regulate synaptic plasticity in a slower fashion by increasing, for example, the genetic expression of cholinergic nicotinic (Takita and Muramatsu, 1995) and muscarinic receptors (Takayama et al., 1987; Mizukawa et al., 1989; Gonzalez and Pazos, 1992; Kaufer et al., 1998; Brand et al., 2008). Our findings indicating that a blockade of glucocorticoid signaling prevented memory enhancement induced by oxotremorine and, conversely, that a blockade of muscarinic receptors prevented memory enhancement induced by corticosterone, suggest that glucocorticoids might be involved in mediating at least some of these stress effects on the cholinergic system. 
There is some evidence in other brain regions indicating interactions between glucocorticoids and the cholinergic system. An in vivo microdialysis study reported that complete removal of glucocorticoids by adrenalectomy enhanced hippocampal levels of acetylcholine in response to potassium chloride stimulation (Mizoguchi et al., 2008). Another study investigated the interaction between glucocorticoids and the cholinergic system within the BLA in enhancing memory consolidation of inhibitory avoidance training (Power et al., 2000). Consistent with the current findings, blockade of muscarinic cholinergic activity within the BLA with atropine prevented the memory-enhancing effect of a concurrently administered GR agonist. In view of the evidence that glucocorticoids enhance memory consolidation by facilitating arousal-induced noradrenergic activation within the BLA (Quirarte et al., 1997; Roozendaal, 2002; Roozendaal et al., 2006), these findings were interpreted in support of the view that noradrenergic activation requires downstream cholinergic signaling within the BLA in enhancing memory consolidation (IntroiniCollison and McGaugh, 1988; Decker et al., 1990). Although very little is known concerning a possible involvement of the noradrenergic system within the dorsal striatum in memory consolidation, findings from our laboratory indicate that noradrenergic activity within the dorsal striatum is essential for mediating glucocorticoid effects memory consolidation (Espinoza-González et al., 2007). Thus, such findings suggest that glucocorticoids migh interact with the cholinergic system indirectly via an activation of the noradrenergic system. However, the other findings of the current study indicating that a blockade of glucocorticoid signaling with either metyrapone or GR antagonist also prevented the memory-enhancing effect of the muscarinic receptor agonist oxotremorine cannot be readily explained by such a mechanism: previous findings indicated that a blockade of $\beta$-adrenoceptor activity within the BLA does not block the memory-enhancing effect of a muscarinic receptor agonist (Introini-Collison et al., 1996). Thus, these findings indicating that cholinergic effects on memory consolidation require concurrent glucocorticoid signaling suggest that glucocorticoids might also act within the dorsal striatum at a level that is downstream of the cholinergic system.

As glucocorticoids and muscarinic receptor agonists are known to act in many different brain regions, including the BLA, hippocampus, and prefrontal cortex, in enhancing memory consolidation of inhibitory avoidance training (Roozendaal and McGaugh, 1997b; Roozendaal et al., 1999; Barsegyan et al., 2010), what is so interesting about their effects in dorsal striatum? In inhibitory avoidance, rats learn that they receive footshock in a particular place. Previously, we developed a modified inhibitory avoidance procedure to investigate which components of the inhibitory avoidance training experience (i.e., memory of the

\section{REFERENCES}

Akirav, I., Kozenicky, M., Tal, D., Sandi, C., Venero, C., and Richter-Levin, G. (2004). A facilitative role for corticosterone in the acquisition of a spatial task under moderate stress. Learn. Mem. 11, 188-195.

Baratti, C. M., Huygens, P., Mino, J., Merlo, A., and Gardella, J. (1979).

context or the footstock were influenced by our drug manipulations). Whereas a GR agonist or oxotremorine infused into the BLA enhanced memory of both the contextual and footshock components of inhibitory avoidance training (Malin et al., 2007; Roozendaal et al., 2009), the same drugs infused into the hippocampus selectively enhanced memory of the contextual information of the task (Malin et al., 2007; Roozendaal et al., 2009). However, corticosterone administration into the dorsal striatum did not enhance memory of either the contextual or aversively motivational aspects of the task (Medina et al., 2007). In view of the evidence that the dorsal striatum is essentially involved in learning and memory of procedural or implicit forms of training (Jog et al., 1999; DeCoteau and Kesner, 2000; Packard et al., 2001; Packard and Wingard, 2004; Reiss et al., 2005; Izquierdo et al., 2006; Packard, 2009), these findings led to the suggestion that glucocorticoids might act within the dorsal striatum to selectively enhance memory consolidation of procedural aspects of inhibitory avoidance training. This view was supported by the finding that corticosterone infused into the dorsal striatum after water maze training also selectively enhanced memory of cued training, without affecting memory of spatial training (Quirarte et al., 2009). Thus, these findings indicate that although glucocorticoids and cholinergic system act in many different brain regions to enhance memory consolidation of inhibitory avoidance training, each of the brain regions might contribute in a unique fashion to enhance the consolidation of memory of specific components of information acquired during the task.

In summary, the findings presented in this work indicate that memory consolidation of inhibitory avoidance learning is facilitated by the concurrent activity of the striatal cholinergic system and glucocorticoids. Based on our prior studies, they further suggest that it is the memory of the procedural attributes of this task that was influenced by these interactions. It would seem important to determine whether the striatal cholinergic system is actually involved in the procedural aspects of inhibitory avoidance memory, as in the case of glucocorticoids in this brain region.

\section{ACKNOWLEDGMENTS}

The authors thank Martín García, Angel Méndez, Leopoldo González, and Leonor Casanova for excellent technical assistance. This research was supported by grants DGAPA-PAPIITUNAM (IN214111) and CONACYT 130524. This work was carried out in partial fulfillment of the requirements to obtain the Doctor's Degree (Doctorado en Ciencias Biomédicas, UNAM) by O. Sánchez-Resendis, who was a recipient of a Graduate Scholarship from CONACYT (16317) and PDCB of CGEPUNAM (90854363).

cortex enhance memory consolidation and impair working memory by a common neural mechanism. Proc. Natl. Acad. Sci. U.S.A. 107, 16655-16660.

Bermúdez-Rattoni, F., MujicaGonzalez, M., and Prado-Alcalá, R. A. (1986). Is cholinergic activity of the striatum involved in the acquisition of positively-motivated behaviors? Pharmacol. Biochem. Behav. 24, 715-719.

Brand, L., Groenewald, I., Stein, D. J., Wegener, G., and Harvey, B. H. (2008). Stress and re-stress increases conditioned taste aversion learning in rats: possible frontal cortical and hippocampal muscarinic receptor 
involvement. Eur. J. Pharmacol. 586, 205-211.

Brimblecombe, R. W. (1964). "Effects of centrally acting drugs on acquisition of a passive avoidance reaction in the rat," in NeuroPsychopharmacology, eds D. Bente and P. B. Bradley (Amsterdam: Elsevier), 333-336.

Conboy, L., and Sandi, C. (2010). Stress at learning facilitates memory formation by regulating AMPA receptor trafficking through a glucocorticoid action. Neuropsychopharmacology, 35, 674-685.

Decker, M. W., Gill, T. M., and McGaugh, J. L. (1990). Concurrent muscarinic and beta-adrenergic blockade in rats impairs placelearning in a water maze and retention of inhibitory avoidance. Brain Res. 513, 81-85.

DeCoteau, W. E., and Kesner, R. P. (2000). A double dissociation between the rat hippocampus and medial caudoputamen in processing two forms of knowledge. Behav. Neurosci. 114, 1096-1108.

de Kloet, E. R., Oitzl, M. S., and Joëls, M. (1999). Stress and cognition: are corticosteroids good or bad guys? Trends Neurosci. 22, 422-426.

Espinoza-González, V., Charles, J., Serafín, N., Prado-Alcalá, R. A., Roozendaal, B., and Quirarte, G. (2007). "Basolateral amygdalastriatal interactions in regulating glucocorticoid effects on memory consolidation," in 37th Annual Meeting, Society for Neuroscience, (San Diego, CA, USA), 308-322.

Flood, J. F., Vidal, D. L., Bennett, E. L., Orme, A. E., Vasquez, S., and Jarvik, M. E. (1978). Memory facilitating and anti-amnesic effects of corticosteroids. Pharmacol. Biochem. Behav. 8, 81-87.

Galarraga, E., Hernandez-Lopez, S., Reyes, A., Miranda, I., BermudezRattoni, F., Vilchis, C., and Bargas, J. (1999). Cholinergic modulation of neostriatal output: a functional antagonism between different types of muscarinic receptors. J. Neurosci. 19, 3629-3638.

Giordano, M., and Prado-Alcalá, R. A. (1986). Retrograde amnesia induced by post-trial injection of atropine into the caudate-putamen. Protective effect of the negative reinforcer. Pharmacol. Biochem. Behav. 24, 905-909.

Gold, P. E. (2003). Acetylcholine modulation of neural systems involved in learning and memory. Neurobiol. Learn. Mem. 80, 194-210.

Gonzalez, A. M., and Pazos, A. (1992). Affinity changes in muscarinic acetylcholine receptors in the rat brain following acute immobilization stress: an autoradiographic study. Eur. J. Pharmacol. 214, 261-268.

Graybiel, A. M. (2008). Habits, rituals, and the evaluative brain. Annu. Rev. Neurosci. 31, 359-387.

Haycock, J. W., Deadwyler, S. A., Sideroff, S. I., and McGaugh, J. L. (1973). Retrograde amnesia and cholinergic systems in the caudateputamen complex and dorsal hippocampus of the rat. Exp. Neurol. 41, 201-213.

Helm, K. A., Ziegler, D. R., and Gallagher, M. (2004). Habituation to stress and dexamethasone suppression in rats with selective basal forebrain cholinergic lesions. Hippocampus 14, 628-635.

Introini-Collison, I. B., Dalmaz, C., and McGaugh, J. L. (1996). Amygdala beta-noradrenergic influences on memory storage involve cholinergic activation. Neurobiol. Learn. Mem. $65,57-64$.

Introini-Collison, I. B., and McGaugh, J. L. (1988). Modulation of memory by post-training epinephrine: involvement of cholinergic mechanisms. Psychopharmacology 94, 379-385.

Izquierdo, I., Bevilaqua, L. R., Rossato, J. I., Bonini, J. S., Da Silva, W. C., Medina, J. H., and Cammarota, M. (2006). The connection between the hippocampal and the striatal memory systems of the brain: a review of recent findings. Neurotox. Res. 10, 113-121.

Joëls, M., Fernandez, G., and Roozendaal, B. (2011). Stress and emotional memory: a matter of timing. Trends Cogn. Sci. 15, 280-288.

Jog, M. S., Kubota, Y., Connolly, C. I., Hillegaart, V., and Graybiel, A. M. (1999). Building neural representations of habits. Science 286, 1745-1749.

Kaufer, D., Friedman, A., Seidman, S., and Soreq, H. (1998). Acute stress facilitates long-lasting changes in cholinergic gene expression. Nature 393, 373-377.

Loscertales, M., Rose, S. P. R., and Sandi, C. (1997). The corticosteroid synthesis inhibitors metyrapone and aminoglutethimide impair long-term memory for a passive avoidance task in day-old chicks. Brain Res. 769, 357-361.

Malin, E. L., Ibrahim, D. Y., Tu, J. W., and McGaugh, J. L. (2007). Involvement of the rostral anterior cingulate cortex in consolidation of inhibitory avoidance memory: interaction with the basolateral amygdala. Neurobiol. Learn. Mem. 87, 295-302.

Mark, G. P., Rada, P. V., and Shors, T. J. (1996). Inescapable stress enhances extracellular acetylcholine in the rat hippocampus and prefrontal cortex but not the nucleus accumbens or amygdala. Neuroscience 74, 767-774.

McDonald, R. J., and White, N. M. (1993). A triple dissociation of memory systems: Hippocampus, amygdala, and dorsal striatum. Behav. Neurosci. 107, 3-22.

McGaugh, J. L. (2004). The amygdala modulates the consolidation of memories of emotionally arousing experiences. Annu. Rev. Neurosci. 27, 1-28.

Medina, A. C., Charles, J. R., EspinozaGonzález, V., Sánchez-Resendis, O., Prado-Alcalá, R. A., Roozendaal, B., and Quirarte, G. L. (2007). Glucocorticoid administration into the dorsal striatum facilitates memory consolidation of inhibitory avoidance training but not of the context or footshock components. Learn. Mem. 14, 673-677.

Miranda, M. I., Quirarte, G. L., Rodriguez-Garcia, G., McGaugh, J. L., and Roozendaal, B. (2008). Glucocorticoids enhance taste aversion memory via actions in the insular cortex and basolateral amygdala. Learn. Mem. 15, 468-476.

Mizoguchi, K., Shoji, H., Ikeda, R., Tanaka, Y., Maruyama, W., and Tabira, T. (2008). Suppression of glucocorticoid secretion enhances cholinergic transmission in rat hippocampus. Brain Res. Bull. 76, 612-615.

Mizukawa, K., Vincent, S. R., McGeer, P. L., and McGeer, E. G. (1989). Distribution of reduced-nicotinamide-adenine-din ucleotide-phosphate diaphorasepositive cells and fibers in the cat central nervous system. J. Comp. Neurol. 279, 281-311.

Neill, D. B., and Grossman, S. P. (1970). Behavioral effects of lesions or cholinergic blockade of the dorsal and ventral caudate of rats. J. Comp. Physiol. Psychol. 71, 311-317.

Orsini, C., Castellano, C., and Cabib, S. (2001). Pharmacological evidence of muscarinic-cholinergic sensitization following chronic stress. Psychopharmacology 155, 144-147.

Ortega, A., del Guante, M. A., PradoAlcalá, R. A., and Alemán, V. (1996). Changes in rat brain muscarinic receptors after inhibitory avoidance learning. Life Sci. 58, 799-809.
Packard, M. G. (2009). Anxiety, cognition, and habit: a multiple memory systems perspective. Brain Res. 1293, 121-128.

Packard, M. G., Cahill, L., and McGaugh, J. L. (1994). Amygdala modulation of hippocampaldependent and caudate nucleus-dependent memory processes. Proc. Natl. Acad. Sci. U.S.A. 91, 8477-8481.

Packard, M. G., Introini-Collison, I., and McGaugh, J. L. (1996). Stria terminalis lesions attenuate memory enhancement produced by intracaudate nucleus injections of oxotremorine. Neurobiol. Learn. Mem. 65, 278-282.

Packard, M. G., and Knowlton, B. J. (2002). Learning and memory functions of the basal ganglia. Annu. Rev. Neurosci. 25, 563-593.

Packard, M. G., Vecchioli, S. F., Schroeder, J. P., and Gasbarri, A. (2001). Task-dependent role for dorsal striatum metabotropic glutamate receptors in memory. Learn. Mem. 8, 96-103.

Packard, M. G., and White, N. M. (1991). Dissociation of hippocampus and caudate nucleus memory systems by posttraining intracerebral injection of dopamine agonists. Behav. Neurosci. 105, 295-306.

Packard, M. G., and Wingard, J. C. (2004). Amygdala and "emotional" modulation of the relative use of multiple memory systems. Neurobiol. Learn. Mem. 82, 243-252.

Paxinos, G., and Watson, C. (2005). The Rat Brain in Stereotaxic Coordinates, 4th edn. San Diego, CA: Academic Press.

Pisani, A., Bonsi, P., Picconi, B., Tolu, M., Giacomini, P., and Scarnati, E. (2001). Role of tonically-active neurons in the control of striatal function: cellular mechanisms and behavioral correlates. Prog. Neuropsychopharmacol. Biol. Psychiatry 25, 211-230.

Power, A. E., Roozendaal, B., and McGaugh, J. L. (2000). Glucocorticoid enhancement of memory consolidation in the rat is blocked by muscarinic receptor antagonism in the basolateral amygdala. Eur. J. Neurosci. 12, 3481-3487.

Prado-Alcalá, R. A., Cepeda, G., Verduzco, L., Jimenez, A., and Vargas-Ortega, E. (1984a). Effects of cholinergic stimulation of the caudate nucleus on active avoidance. Neurosci. Lett. 51, 31-36. Prado-Alcalá, R. A., Signoret-Edward, L., Figueroa, M., Giordano, M., and Barrientos, M. A. (1984b). 
Post-trial injection of atropine into the caudate nucleus interferes with long-term but not with short-term retention of passive avoidance. Behav. Neural. Biol. 42, 81-84.

Prado-Alcalá, R. A., Cruz-Morales, S. E., and Lopez-Miro, F. A. (1980). Differential effects of cholinergic blockade of anterior and posterior caudate nucleus on avoidance behaviors. Neurosci. Lett. 18, 339-345.

Prado-Alcalá, R. A., FernandezSamblancat, M., and Solodkin-Herrera, M. (1985). Injections of atropine into the caudate nucleus impair the acquisition and the maintenance of passive avoidance. Pharmacol. Biochem. Behav. 22, 243-247.

Prado-Alcalá, R. A., Ruiloba, M. I., Rubio, L., Solana-Figueroa, R., Medina, C., Salado-Castillo, R., and Quirarte, G. L. (2003). Regional infusions of serotonin into the striatum and memory consolidation. Synapse 47, 169-175.

Quirarte, G. L., de la Teja, I. S., Casillas, M., Serafín, N., PradoAlcalá, R. A., and Roozendaal, B. (2009). Corticosterone infused into the dorsal striatum selectively enhances memory consolidation of cued water-maze training. Learn. Mem. 16, 586-589.

Quirarte, G. L., Roozendaal, B., and McGaugh, J. L. (1997). Glucocorticoid enhancement of memory storage involves noradrenergic activation in the basolateral amygdala. Proc. Natl. Acad. Sci. U.S.A. 94, 14048-14053.

Reiss, J. P., Campbell, D. W., Leslie, W. D., Paulus, M. P., Stroman, P. W., Polimeni, J. O., Malcolmson, K. A., and Sareen, J. (2005). The role of the striatum in implicit learning: a functional magnetic resonance imaging study. Neuroreport 16, 1291-1295.

Roozendaal, B. (2002). Stress and memory: opposing effects of glucocorticoids on memory consolidation and memory retrieval. Neurobiol. Learn. Mem. 78, 578-595.

Roozendaal, B., Bohus, B., and McGaugh, J. L. (1996). Dosedependent suppression of adrenocortical activity with metyrapone: effects on emotion and memory. Psychoneuroendocrinology 21, 681-693.

Roozendaal, B., Hui, G. K., Hui, I. R., Berlau, D. J., McGaugh, J. L., and Weinberger, N. M. (2006). Basolateral amygdala noradrenergic activity mediates corticosterone-induced enhancement of auditory fear conditioning. Neurobiol. Learn. Mem. 86, 249-255.

Roozendaal, B., McEwen, B. S., and Chattarji, S. (2009). Stress, memory and the amygdala. Nat. Rev. Neurosci. 10, 423-433.

Roozendaal, B., and McGaugh, J. L. (1997a). Basolateral amygdala lesions block the memoryenhancing effect of glucocorticoid administration in the dorsal hippocampus of rats. Eur. J. Neurosci. 9, 76-83.

Roozendaal, B., and McGaugh, J. L. (1997b). Glucocorticoid receptor agonist and antagonist administration into the basolateral but not central amygdala modulates memory storage. Neurobiol. Learn. Mem. 67, 176-179.

Roozendaal, B., Nguyen, B. T., Power, A. E., and McGaugh, J. L. (1999). Basolateral amygdala noradrenergic influence enables enhancement of memory consolidation induced by hippocampal glucocorticoid receptor activation. Proc. Natl. Acad. Sci. U.S.A. 96, 11642-11647.

Sandberg, K., Sanberg, P. R., and Coyle, J. T. (1984). Effects of intrastriatal injections of the cholinergic neurotoxin AF64A on spontaneous nocturnal locomotor behavior in the rat. Brain Res. 299, 339-343.

Sandi, C., and Rose, S. P. (1994). Corticosterone enhances long-term retention in one-day-old chicks trained in a weak passive avoidance learning paradigm. Brain Res. 647, 106-112.

Schwabe, L., Joëls, M., Roozendaal, B., Wolf, O. T., and Oitzl, M. S. (2012). Stress effects on memory: an update and integration. Neurosci. Biobehav. Rev. doi: 10.1016/j.neubiorev.2011.07.002. [Epub ahead of print].

Shinoe, T., Matsui, M., Taketo, M. M. and Manabe, T. (2005). Modulation of synaptic plasticity by physiological activation of M1 muscarinic acetylcholine receptors in the mouse hippocampus. J. Neurosci. 25, 11194-11200.

Solana-Figueroa, R., and Prado-Alcalá, R. A. (1990). Retrograde amnesia produced by intrastriatal atropine and its reversal by choline. Life Sci. 46, 679-686.

Tajima, T., Endo, H., Suzuki, Y., Ikari, H., Gotoh, M., and Iguchi, A. (1996). Immobilization stressinduced increase of hippocampal acetylcholine and of plasma epinephrine, norepinephrine and glucose in rats. Brain Res. 720, 155-158.

Takayama, H., Mizukawa, K., Ota, Z., and Ogawa, N. (1987). Regional responses of rat brain muscarinic cholinergic receptors to immobilization stress. Brain Res. 436, 291-295.

Takita, M., and Muramatsu, I. (1995). Alteration of brain nicotinic receptors induced by immobilization stress and nicotine in rats. Brain Res. 681, 190-192.

White, N. M. (2009). Some highlights of research on the effects of caudate nucleus lesions over the past 200 years. Behav. Brain Res. 199, 3-23.

Wilson, C. J. (2004). "Basal ganglia," in The Synaptic Organization of the Brain, ed G. M. Shepherd (Oxford, UK: Oxford University Press), 361-414.

Conflict of Interest Statement: The authors declare that the research was conducted in the absence of any commercial or financial relationships that could be construed as a potential conflict of interest.

Received: 25 February 2012; paper pending published: 20 March 2012; accepted: 08 June 2012; published online: 22 June 2012.

Citation: Sánchez-Resendis O, Medina AC, Serafín N, Prado-Alcalá RA, Roozendaal B and Quirarte GL (2012) Glucocorticoid-cholinergic interactions in the dorsal striatum in memory consolidation of inhibitory avoidance training. Front. Behav. Neurosci. 6:33. doi: 10.3389/fnbeh.2012.00033

Copyright (c) 2012 Sánchez-Resendis, Medina, Serafin, Prado-Alcalá, Roozendaal and Quirarte. This is an open-access article distributed under the terms of the Creative Commons Attribution Non Commercial License, which permits non-commercial use, distribution, and reproduction in other forums, provided the original authors and source are credited. 